\title{
Improvement in Wear and Thermal Resistance of Disc Brake Rotors using TiAlN Coating
}

\author{
Satish Kumar $\mathbf{M}^{1}$, Vishal $\mathbf{S}^{2}$, Visisht $\mathbf{V}^{3}$ \\ ${ }^{1}$ Alagappa Chettiar College of Engineering and Technology, Karaikudi, TamilNadu, India \\ ${ }^{2,3}$ SRM University, Chennai, TamilNadu, India
}

\begin{abstract}
In present study, it has been understood that the life of Disc Brakes can be increased by improving the Wear and Thermal resistance of Disc Brake rotors. Thus, a specimen of TVS $200 \mathrm{~mm}$ Disc Brake rotor was chosen to conduct the tests to show the improvements in wear and thermal resistance using Titanium Aluminium Nitride coating on the material. The specimen is tested for finding out its properties and the coating that is already being used. Then, standard tests for Wear resistance and Thermal resistance are conducted for before and after coating criterions to show the improvement in the properties after coating the brake rotors with Titanium Aluminium Nitride.
\end{abstract}

Keywords: Disc Brakes, Coating technology, FEA, Titanium Aluminium Nitride

\section{Introduction}

Mechanical component degradation has drawn more attention in various industrial applications. In harsh working environments, mechanical and chemical attacks subject components to damage, and therefore components degrade over time. This can result in limited load-carrying capacities, reduced system efficiencies, shorter lifetimes, equipment or machinery shutdowns, and even fatal accidents sometimes. The most common mechanical and chemical attacks are wear, erosion, high temperatures and corrosion respectively.

Statistical studies conducted on the attack modes indicate that wear and high temperatures due to friction are important factors that lead to high failure rates in Vehicle brakes, and wear plays a more significant role than corrosion; therefore wear causes more economic losses than corrosion. It has been observed that thermal efficiency also plays a major role in vehicle component. The losses caused by wear and high temperature can be avoided by incorporating effective protection technologies, including improved component design, judicious selection of materials and coatings. There is a significant market demand to support preventing component degradation.

The Objectives of this project are,

- To improve the life of Disc Brakes.

- To improve wear and Thermal resistance of disc brake rotors.

- To conduct suitable experiments and computer simulations to prove that wear and thermal resistance of the Disc Brake rotors has improved by using TiAlN coating.

\section{Coating Methodology}

Coatings are widely used in many industries. Apart from tools, it can be used in electronic industries, decorative purpose, and even for biological and surgical implants. Coatings can vary from a few to several hundred microns. It can be deposited by different means. The coating, its thickness, and means of deposition will depend on the final use of the components and the environment it has to resist. A wide variety of surface coatings are available in today's industry or market. The coating method we have chosen to accomplish our task is Physical Vapour Deposition.

\subsection{Physical Vapour Deposition}

Physical Vapour Deposition (PVD) process, often called thin film process, is an atomistic deposition process. Material is transported from solid or liquid form to atoms or molecules or transported in the form of vapour through vacuum or low pressure gaseous or plasma environment. It condenses when it contacts with the substrates. In PVD process, the deposition rate is from 1 to 10 nanometers per second.

PVD process can be used to deposit films of elements and alloys as well as compounds using reactive deposition processes. In case of reactive deposition, the deposition material reacts with a gaseous environment of co-deposited material to form a film of compound material, such as a nitride, oxide, carbide or carbon nitride.

The main categories of PVD processes are:

- Arc Vapour Deposition,

- Vacuum Deposition,

- Sputter Deposition\&

- Ion Plating.

Each PVD technology generates and deposits material in a different manner and requiring equipment unique to each process. However, all processes utilize the same three essential steps to develop a coating. It includes,

- Vapour phase generation from coating material stock by evaporation, sputtering, arc vaporization or chemical vapour and gases.

- Transfer of the vapour phase from source to substrate by molecular flow or vapour ionization by creating a plasma.

- Deposition and film growth on the substrates. 


\section{International Journal of Science and Research (IJSR) \\ ISSN (Online): 2319-7064}

Index Copernicus Value (2015): 78.96 | Impact Factor (2015): 6.391

These steps can be independent or superimposed on each other depending on the desired coating characteristics. The result of the coating or substrate composite is a function of each material's individual property, the interaction of the materials and process constraints that may exist.

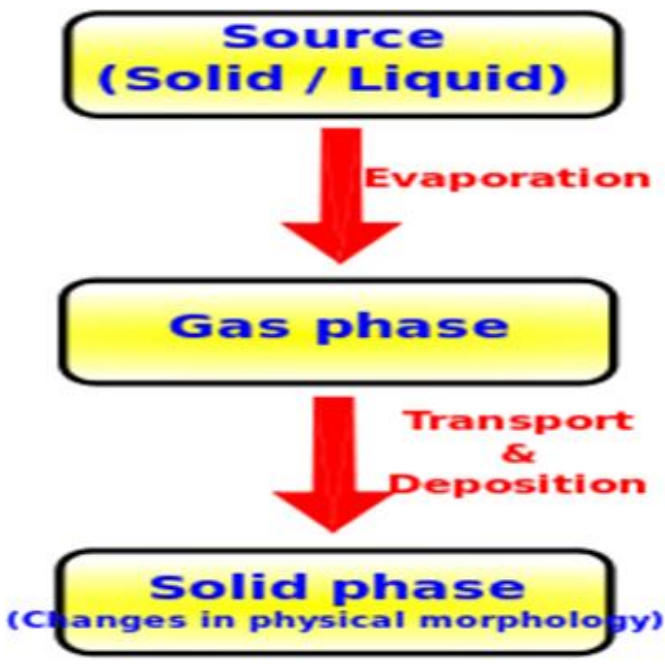

Figure 1: PVD Process

\subsection{Sputtering Deposition}

In the PVD sputtering technique, the vaporization of target material is done through bombardment of the target materials using positive, high-energy noble gas ions such as argon. It requires vacuum conditions and it is used to deposit very thin films on substrates for a wide variety of commercial and scientific purposes. The process requires very low chamber pressures in the range of 10-5 to $10-7$ mbar. Two main purposes necessitating this condition before initiation of sputtering process are contamination minimization and maximization of particle mean free path. Once the vacuum condition is satisfied, a noble gas such as argon (Ar) is backfilled inside the chamber to a pressure of 10-3 mbar to fulfil the role of the bombarding particles.

The deposited coating layer can be of pure material, a compound or an alloy. There are two common ways of sputtering compound materials onto a substrate surface, sputtering of an alloy and reactive sputtering.

\subsection{Coating Material}

Titanium aluminum nitride coating is another titanium based coating that is mainly applied to stainless steel like end mills, drills, saw blades and cutting inserts. The atomic percentage (at. $\%$ ) of titanium/aluminium (Ti/Al) target is $70 \%$ titanium (Ti) and $30 \%$ aluminium (Al). The thickness of the coating on the base material is $4-5 \mu \mathrm{m}$.

\section{Experimental Setup}

This chapter describes the approach and methodology adopted for this project. The activities involved and work flow are summarized. Detailed explanations of the process steps are covered in subsequent sub-chapters.

\subsection{Substrate details}

Objective of the work is to find the optimum value of wear resistance and thermal resistance based on the selected parameters on a TVS Disc brake rotor having a dimension of $\varnothing 200 \mathrm{~mm}$ and $3.1 \mathrm{~mm}$ thickness. The material of the specimen was found to be Stainless steel of GRADE AISI 410 and the composition of the specimen is given below,

Table 1: Composition of Specimen

\begin{tabular}{|c|c|}
\hline Iron & $81 \%$ \\
\hline Manganese & $0.49 \%$ \\
\hline Silicon & $0.43 \%$ \\
\hline Sulphur & $0.007 \%$ \\
\hline Phosphorous & $0.036 \%$ \\
\hline Chromium & $12.29 \%$ \\
\hline Carbon & $0.150 \%$ \\
\hline Coating already present & Simple Epoxy $(20 \mu \mathrm{m})$ \\
\hline
\end{tabular}

\subsection{Cleaning}

The condition and reproducibility of the substrate surface is an integral part of any PVD processing. In most cases, the surface condition will be determined by cleaning to remove undesirable contaminants from the surface. A contaminant can be defined as any material on the surface that interferes with the film formation process, affects the film properties in an undesirable way, or influences the film stability in an undesirable way. In most cases, the concern is with both the type and amount of the contaminant.

Contaminants can cover the whole surface such as oxide reaction layers or adsorbed hydrocarbon layers, or they can be limited to restricted areas such as particles or fingerprints. Cleaning is the removal of surface contaminants and is part of what can be termed surface preparation which can also include surface treatments (surface modification) to change the properties of the surface in a desirable way. Cleaning should address local surface conditions such as porosity, embedded particles, steps, roughness, etc. that affects film properties, produce pinholes, and local loss of adhesion. To avoid this problem the substrate is cleaned on the following conditions,

Step 1: Clean substrate with emery sheet of grade IV for surface finish.

Step 2: Substrate dipped in the solution of acetone around 10 $\min$.

Step 3: Substrate dipped in pure water around $5 \mathrm{~min}$.

Step 4: Dry the substrate $10 \mathrm{~min}$.

\subsection{Titanium Aluminum Nitride Coating (PVD)}

The TiAlN coating was done in Oerlikon Balzers Coating India Pvt. Ltd. The coating is done using Physical Vapour Deposition (Sputtering Process) method at $600-700^{\circ} \mathrm{C}$ and coating thickness is $4-5 \mu \mathrm{m}$. The inert gas used is Argon.

Some general information on TiAlN coatings,

1) Can withstand elevated temperatures upto $800^{\circ} \mathrm{C}$ in air.

2) Harder than TiN.

3) Can be applied to most metals to provide enhanced surface

\section{Volume 6 Issue 7, July 2017} www.ijsr.net 


\section{International Journal of Science and Research (IJSR) \\ ISSN (Online): 2319-7064}

Index Copernicus Value (2015): 78.96 | Impact Factor (2015): 6.391

characteristics, and can also be applied to some ceramics and plastics.

\subsection{Wear Test}

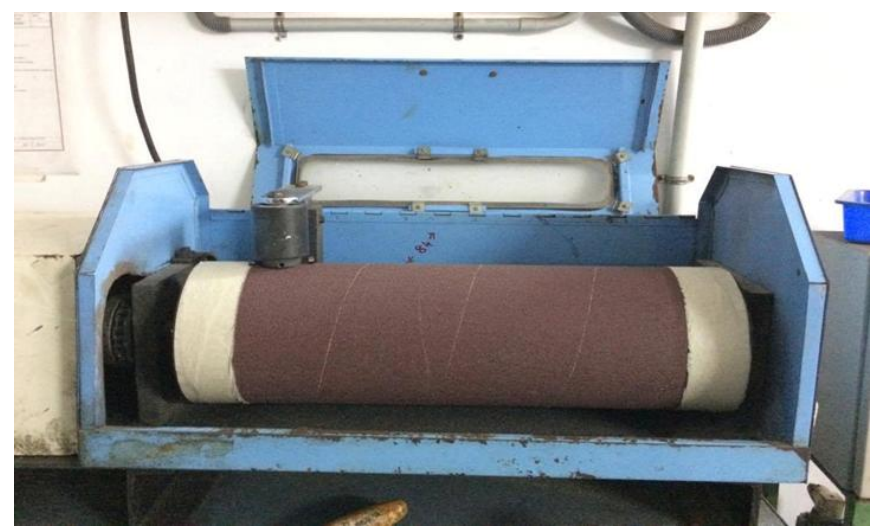

Figure 2: Wear Testing Machine (Rotary Drum Abrader)

\subsubsection{Machine details}

Table 2: Machine details

\begin{tabular}{|c|c|}
\hline Parameters & Values \\
\hline Cylinder Size & $\emptyset 150 \mathrm{~mm} \& 500 \mathrm{~mm}$ \\
\hline Material of coarser abrasive sheet & $60 \mathrm{Grade}$ \\
\hline Equivalent revolution & 84 times \\
\hline Rotational frequency & $40 \pm 1$ \\
\hline Load applied & $1 \mathrm{Kg}$ \\
\hline Standard & ASTM D5963 \\
\hline
\end{tabular}

\subsubsection{Principle}

The wear resistance is measured by moving a test piece across the surface of an abrasive sheet mounted to a revolving drum, and is expressed as volume loss in cubic millimeters or abrasion resistance index in percent. For volume loss, a smaller number indicates better wear resistance.

\subsubsection{Specimen}

Table 3: Material Properties
\begin{tabular}{|c|c|}
\hline Material & AISI 410 \\
\hline Density & $7800 \mathrm{~kg} / \mathrm{m}^{\wedge} 3$ \\
\hline Specific Heat & $28.7 \mathrm{~W} / \mathrm{mK}$ \\
\hline Thermal Conductivity & $460 \mathrm{~J} / \mathrm{kgK}$ \\
\hline Thickness & $3.1 \mathrm{~mm}$ \\
\hline Epoxy coating thickness & $20 \mu \mathrm{m}$ \\
\hline
\end{tabular}

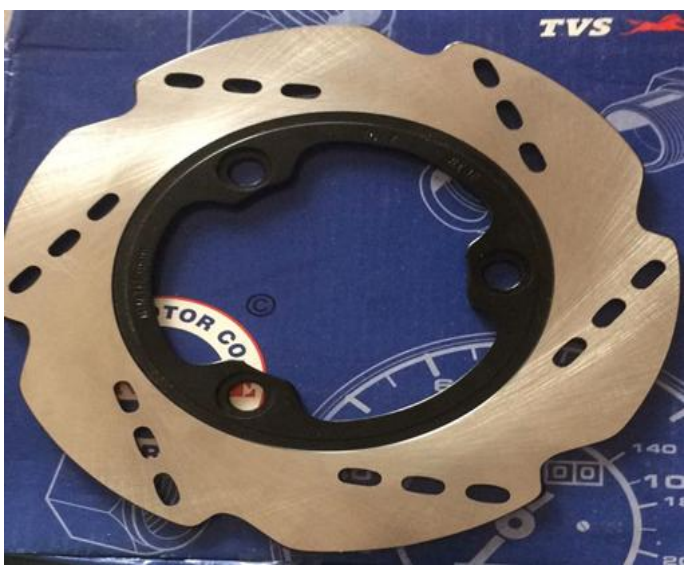

Figure 3: TVS 200 mm Disc Brake Rotor

\subsubsection{Wear Test Results}

(a) Before Coating

By conducting the wear test in the machine before coating with TiAlN the results are obtained,

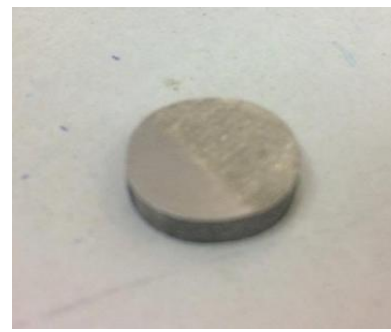

Figure 4: Specimen before coating (wear test)

The material subjected to wear test without the TiAlN coating to find out the wear volume of the disc brake plate.

In this method the result obtained is given in the table, the abrasion loss is 0.0492 and the percentage loss is $0.82 \%$.

Table 4: Before coating test results

\begin{tabular}{|c|c|}
\hline Sample No. & 1 \\
\hline Initial Weight $(\mathrm{g})$ & 5.9807 \\
\hline Final Weight $(\mathrm{g})$ & 5.9315 \\
\hline Abrasion Loss $(\mathrm{g})$ & 0.0492 \\
\hline Percentage $(\%)$ & 0.82 \\
\hline
\end{tabular}

\section{(b) After Coating}

For wear resistance, there are many coatings available in the market. Among those coatings the TiAlN has good hardness, temperature resistance and corrosion resistance properties. Also, it is a newly emerging coating. Thus, it is chosen to improve the wear and thermal resistance of the specimen.

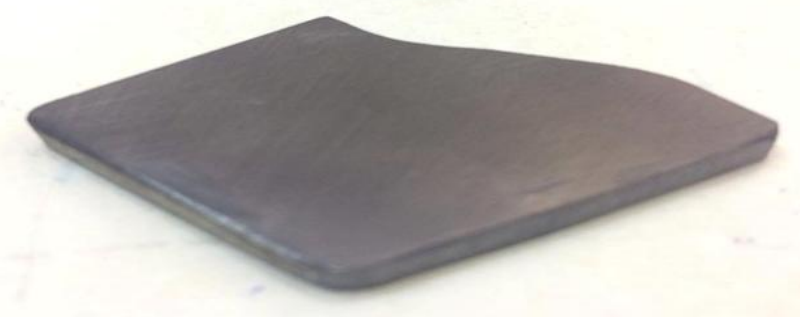

Figure 5: Specimen after coating with TiAlN

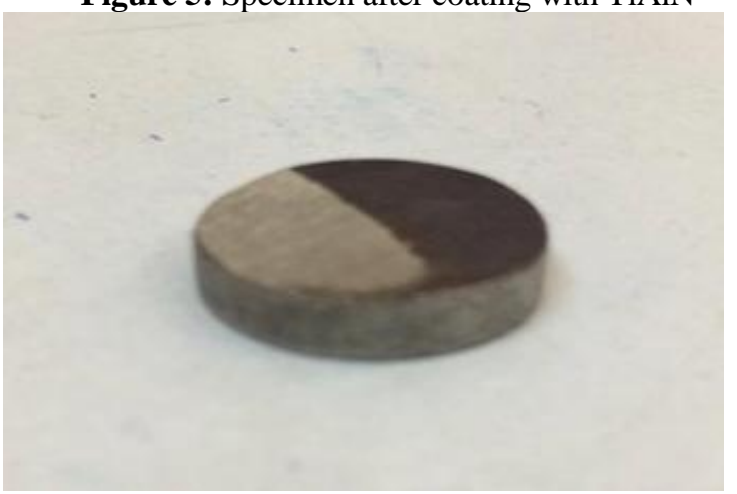

Figure 6: Coated specimen after wear test

The material after the wear test is completed is as shown in the above figure. One side of the material is subjected to wear test and the abrasion loss is calculated in form of subtracting initial to the final weight.

Volume 6 Issue 7, July 2017 www.ijsr.net 


\section{International Journal of Science and Research (IJSR) \\ ISSN (Online): 2319-7064}

Index Copernicus Value (2015): 78.96 | Impact Factor (2015): 6.391

Table 5: Wear test after coating with TiAlN

\begin{tabular}{|c|c|}
\hline Sample No. & 2 \\
\hline Initial Weight $(\mathrm{g})$ & 6.1578 \\
\hline Final Weight $(\mathrm{g})$ & 6.1103 \\
\hline Abrasion Loss $(\mathrm{g})$ & 0.0475 \\
\hline Percentage $(\%)$ & 0.77 \\
\hline
\end{tabular}

\section{(c) Scanning Electron Microscopy (SEM)}

A scanning electron microscope (SEM) is a type of electron microscope that produces images of a sample by scanning the surface with a focused beam of electrons. The electrons interact with atoms in the sample, producing various signals that contain information about the sample's surface topography and composition. The electron beam is scanned in a raster scan pattern, and the beam's position is combined with the detected signal to produce an image. SEM can achieve resolution better than 1 nanometer. Specimens can be observed in high vacuum in conventional SEM, or in low vacuum or wet conditions in variable pressure or environmental SEM, and at a wide range of cryogenic or elevated temperatures with specialized instruments.

This SEM analysis is used to study the surface of the specimen after conducting the wear test on both coated and non-coated materials. A comparison is done between both these specimens to arrive at a solution that the wear resistance has increased after coating the specimen with TiAlN.

\section{(1) Before Coating}

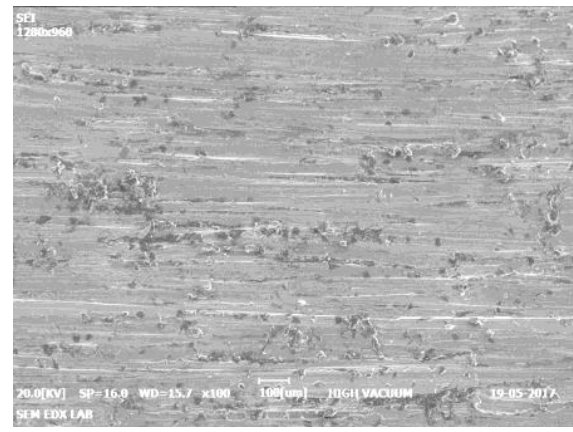

Figure 7: SEM Image before coating with TiAlN

\section{(2) After Coating}

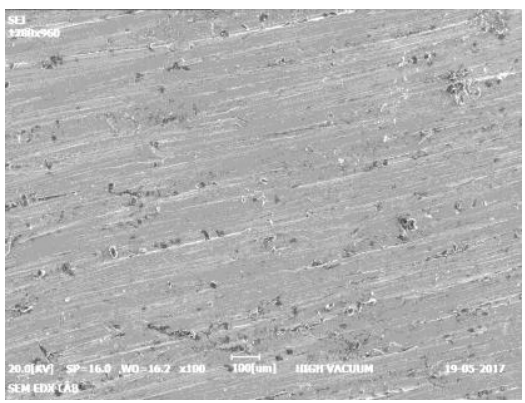

Figure 8: SEM Image after coating with TiAlN

Thus, by comparing the above images it is obvious that the specimen before coating has undergone a lot of wear than the specimen after getting coated. This is evidently because of the increased hardness of Titanium Aluminium Nitride, which is coated on the specimen. Hence, wear resistance has been improved.

\section{(d) Interpretation}

Thus, by conducting these tests on before and after coating criterion of the specimen we could interpret that after coating the specimen with TiAlN $(70 \% \& 30 \%)$ the wear volume has reduced from latter by $0.05 \%$. Hence, showing an obvious improvement in wear resistance. Also, this increase in wear resistance has been proved visually by comparing SEM images.

\subsection{Thermal Test}

Thermal test is conducted using the ANSYS 18.0. There are two types of thermal tests available. Steady state thermal and transient thermal analysis.

In today's growing automotive market the competition for better performance vehicle is growing enormously. People involved will know the importance of a good braking system not only for safety purposes but also to maintain themselves high in the market. The disc brake is a device used for slowing or stopping the motion of a vehicle. A brake disc usually made of cast iron or ceramic composites includes Carbon, Kevlar and Silica, is connected to the wheel and the axle, to stop the wheel. A friction material in the form of brake pads is forced mechanically, hydraulically, pneumatically or electromagnetically against both sides of the disc. This friction causes the disc and attached wheel to slow or stop. Generally, the methodologies like regenerative braking and friction braking system are used in a vehicle. A friction brake generates frictional forces as two or more surfaces rub against each other, to reduce movement. Thus, this friction between the disc brake rotors and the brake linings cause heat at high temperatures upto $400^{\circ} \mathrm{C}$. As a result of high temperatures the rotors tend to deform causing a lower lifetime for the braking system. Hence, suitable materials and coatings must be used to overcome this problem.

\subsubsection{Methodology}

ANSYS Workbench 18.0 was used to conduct the tests relating to show the improvement in Thermal resistance using TiAlN coating on the specimen. The procedure followed to conduct the tests are,

1) A 3D model of the specimen was made using CATIA V5 with thin layers on it to act as coatings.

2) This model was then imported to ANSYS Workbench 18.0 and the layer which was modelled to act as coatings were given contacts as bonded to proceed with further processes.

3) Then, this model was imprinted for a specific area on which braking action takes place.

4) And boundary conditions were applied to conduct steady state and transient thermal analysis.

5) Finally, solutions were taken from the module to make a comparison between before and after coating criterions.

\subsubsection{Calculations for Input Parameters}

In the aspect of the vehicle accident prevention, the braking performance of vehicles has been a critical issue. The heat flux is calculated for the vehicle stopping distance of $7 \mathrm{~m}$ (assumption) and the following input parameters are derived from calculations.

Mass of the Vehicle $=140 \mathrm{~kg}$

Stopping distance of Vehicle $(\mathrm{d})=7 \mathrm{~m}$

Volume 6 Issue 7, July 2017 www.ijsr.net 


\section{International Journal of Science and Research (IJSR) \\ ISSN (Online): 2319-7064}

Index Copernicus Value (2015): 78.96 | Impact Factor (2015): 6.391

Final Velocity $=0 \mathrm{~m} / \mathrm{s}$

Brake rotor diameter $(\mathrm{D})=200 \mathrm{~mm}$ (or) $0.2 \mathrm{~m}$

Thermal conductivity $(\mathrm{k})=0.9$

Inner radius of Pad $(\mathrm{R} 1)=65 \mathrm{~mm}$

Outer radius of $\mathrm{Pad}(\mathrm{R} 2)=85 \mathrm{~mm}$

Acceleration due to gravity $(\mathrm{g})=9.81 \mathrm{~m} / \mathrm{s}^{2}$

Co-efficient of friction for dry pavement $=0.7$

Maximum Temperature on Disc $=325^{\circ} \mathrm{C}$

\section{(a) Parameters derived after calculations}

Table 6: Input Parameters

\begin{tabular}{|c|c|}
\hline Initial speed (u) & $9.8 \mathrm{~m} / \mathrm{s}$ \\
\hline Deceleration (a) & $2.5 \mathrm{~m} / \mathrm{s}^{2}$ \\
\hline Stopping time (t) & $3.92 \mathrm{~s}$ \\
\hline Total Energy (E) & $6924 \mathrm{~J}$ \\
\hline Heat Generated (Q) & $102120 \mathrm{~J}$ \\
\hline Power $\left(P_{h}\right)$ & $26051.02 \mathrm{~W}$ \\
\hline Usable Disc Area (A) & $2.35 \mathrm{~m}^{2}$ \\
\hline Heat Flux $\left(Q_{h}\right)$ & $11085 \mathrm{~W} / \mathrm{m}^{2}$ \\
\hline Flim Coefficient $\left(h_{r}\right)$ & $37 \mathrm{Wm}^{20} \mathrm{C}$ \\
\hline
\end{tabular}

\subsubsection{D Modelling using CATIA V5}

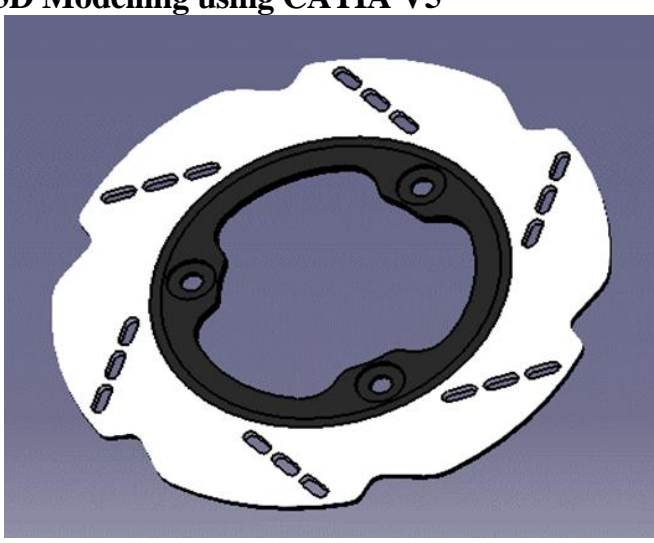

Figure 9: 3D Model of the Specimen

\subsubsection{Steady State Thermal Analysis}

A steady-state thermal analysis calculates the effects of steady thermal loads on a system or component.

Table 7: AISI 410 Material Properties

\begin{tabular}{|c|c|}
\hline Density & $7800 \mathrm{~kg} / \mathrm{m}^{3}$ \\
\hline Thermal Conductivity & $28.7 \mathrm{~W} / \mathrm{mK}$ \\
\hline Specific Heat & $460 \mathrm{~J} / \mathrm{kg} \mathrm{K}$ \\
\hline Thickness & $3.1 \mathrm{~mm}$ \\
\hline
\end{tabular}

Table 8: Epoxy resin material Properties

\begin{tabular}{|c|c|}
\hline Density & $1300 \mathrm{~kg} / \mathrm{m}^{3}$ \\
\hline Thermal Conductivity & $0.35 \mathrm{~W} / \mathrm{mK}$ \\
\hline Specific Heat & $8.5 e^{7} \mathrm{~Pa}$ \\
\hline Thickness & $1.9 e^{8} \mathrm{~Pa}$ \\
\hline
\end{tabular}

Table 9: TiAlN material properties

\begin{tabular}{|c|c|}
\hline Density & $6340 \mathrm{~kg} / \mathrm{m}^{3}$ \\
\hline Thermal Conductivity & $4.94 \mathrm{~W} / \mathrm{mK}$ \\
\hline Specific Heat & $1500 \mathrm{~J} / \mathrm{kg} \mathrm{K}$ \\
\hline Thickness & 3 to 4 microns \\
\hline
\end{tabular}

(a) Meshing Details

The goal of meshing in ANSYS Workbench is to provide robust, easy to use meshing tools that will simplify the mesh generation process. The model used must be divided into a number of small pieces known as finite elements. Since the model is divided into a number of discrete parts, in simple terms, a mathematical net or "mesh" is required to carry out a finite element analysis.

A finite element mesh model generated is shown below. The elements used for the mesh of the model are tetrahedral threedimensional elements with 8 nodes.

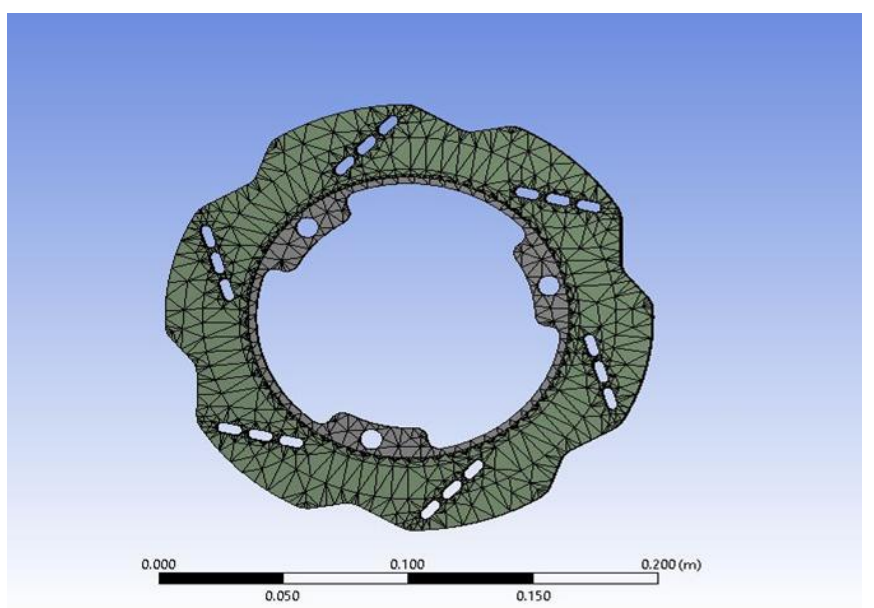

Figure 10: Meshed model

Table 10: Mesh Details

\begin{tabular}{|c|c|}
\hline No. of Elements & 14118 \\
\hline No. of Nodes & 34225 \\
\hline
\end{tabular}

(b) Results

(1) Steady State Thermal Analysis before coating with TiAlN

In this steady state thermal analysis the results obtained shows a maximum temperature of $\mathbf{9 0}$ degree celsius on the rotor.

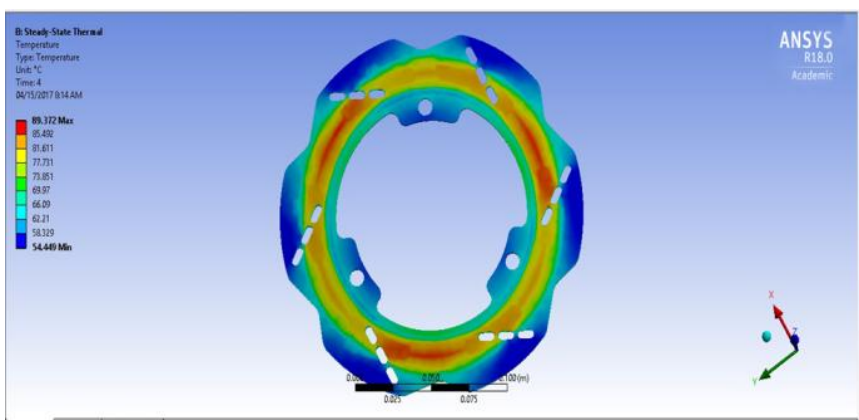

Figure 11: Steady State thermal before coating (epoxy)

\section{(2) Steady State Thermal Analysis after coating with TiAlN}

In this analysis layers of TiAlN are bonded with the rotor material as a coating and input parameters are provided. And, the results show a maximum temperature of $\mathbf{7 6}$ degree Celsius on the rotor.

\section{Volume 6 Issue 7, July 2017 www.ijsr.net}




\section{International Journal of Science and Research (IJSR) \\ ISSN (Online): 2319-7064}

Index Copernicus Value (2015): 78.96 | Impact Factor (2015): 6.391

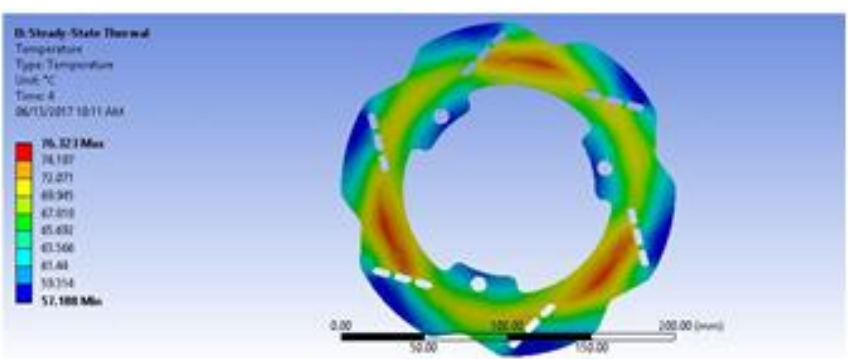

Figure 12: Steady State thermal after coating with TiAlN coating

Thus, there is an obvious decrease in maximum temperature obtained by the specimen after coating it with Titanium Aluminium Nitride for the same operational parameters.

\subsubsection{Transient Thermal Analysis}

A transient thermal analysis follows basically the same procedures as a steady-state thermal analysis. The main difference is that most applied loads in a transient analysis are functions of time.

Table 11: Analysis Parameters

\begin{tabular}{|c|c|}
\hline No. of Steps & 4 \\
\hline Time & 4 seconds \\
\hline Initial Temperature & $22^{\circ} \mathrm{C}$ \\
\hline
\end{tabular}

(a) Transient Thermal Analysis before coating with TiAIN

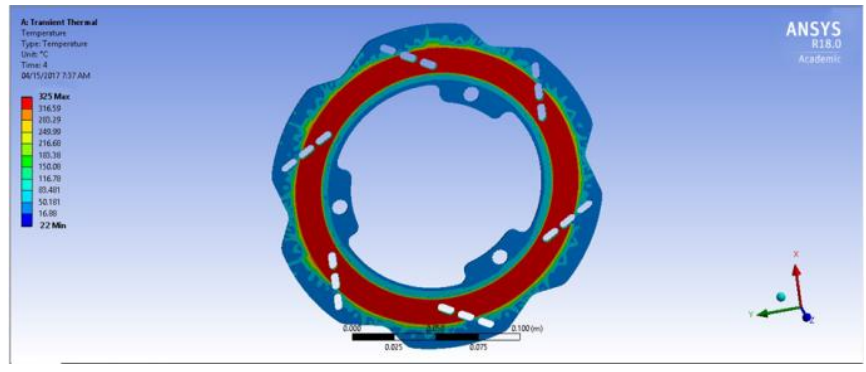

Figure 13: Step $4-325^{\circ} \mathrm{C}$ (without coating)

(b) Transient Thermal Analysis after coating with TiAIN

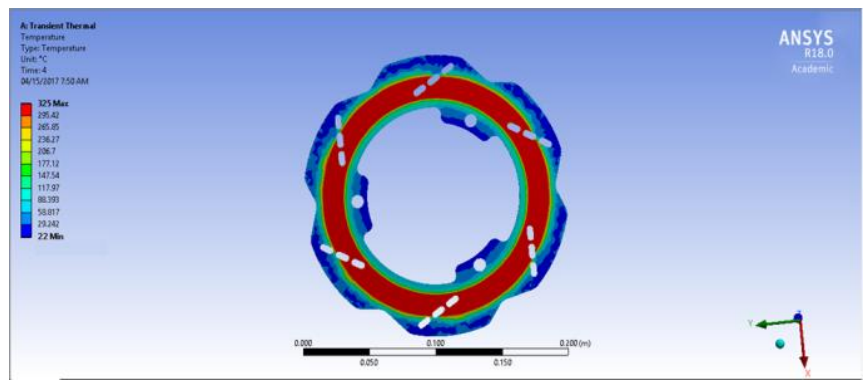

Figure 14: Step $4-325^{\circ} \mathrm{C}$ (with coating)

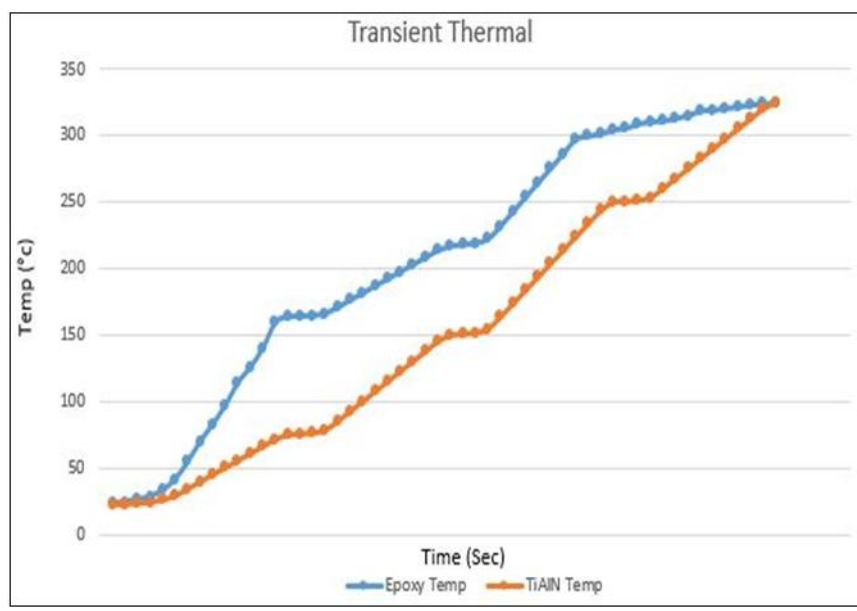

Figure 15: Plot between time and temperature for before and after coating criterions

The transient thermal analysis is conducted using the same model that was used in steady state thermal analysis. But, the difference here was to see how the temperature varies with time (stopping time was approximately derived as 4 seconds) on the specimen with the same operational parameters.

The model for without coating criterion was with epoxy layer on it and the model for with coating criterion had an additional layer of TiAlN. All these layers were bonded together to obtain the required results. After obtaining the required results, these were compared using a plot between time and temperature.

The above plot evidently shows that the specimen before coating (blue line) with TiAlN has reached high temperatures corresponding to time function when compared with the specimen coated with TiAlN (red line). As, it is visually obvious that the red line follows a steady path to reach the maximum temperature of $325^{\circ} \mathrm{C}$ than the blue line this proves that the specimen coated with TiAlN has good thermal resistance throughout the braking process.

\subsubsection{Heat Flux}

Heat flux or thermal flux is the rate of heat energy transfer through a given surface per unit time. The SI derived unit of heat rate is joule per second, or watt. Heat flux density is the heat rate per unit area.

(a) Heat Flux of Specimen before coating with TiAlN Maximum Heat Flux $=0.58181 \mathrm{~W} / \mathrm{mm}^{2}$

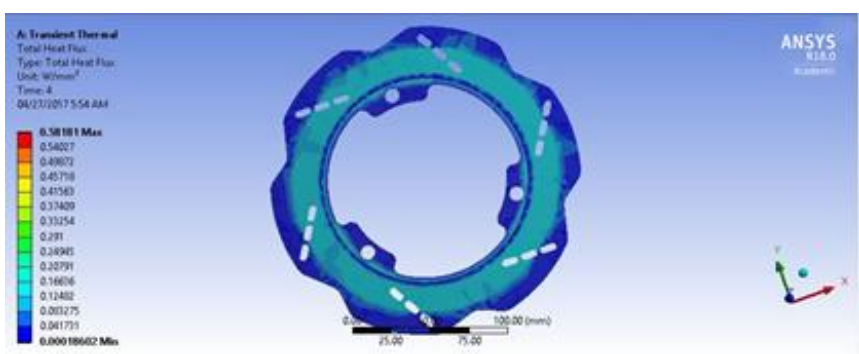

Figure 16: Heat Flux - before coating

(b) Heat flux of Specimen after coating with TiAIN Maximum Heat Flux $=1.9942 \mathrm{~W} / \mathrm{mm}^{\mathrm{a}}$ 


\section{International Journal of Science and Research (IJSR) \\ ISSN (Online): 2319-7064}

Index Copernicus Value (2015): 78.96 | Impact Factor (2015): 6.391

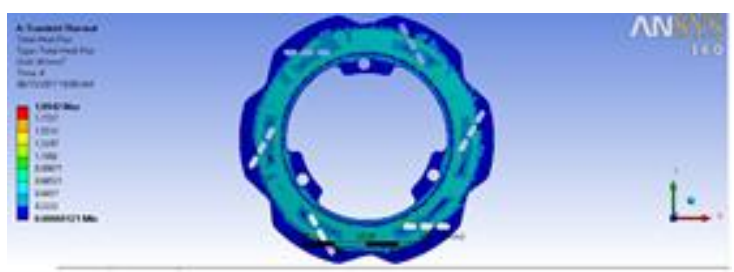

Figure 17: Heat Flux - after coating

Thus, knowing the maximum heat flux for both before and after coating criterions we could assert that the heat transfer per unit area has increased by a vast percentage. Hence, a proved improvement in thermal resistance of the specimen after coating it with Tiatanium Aluminium Nitruide is seen.

\section{Results and Discussion}

\subsection{Wear Test}

Our objective is to reduce the wear in the disc brake plate by coating it with titanium aluminium nitride.

- Percentage of wear loss before coating is $0.82 \%$ and after coating is $0.77 \%$.Hence, an obvious improvement in wear resistance after coating the specimen with TiAlN is witnessed.

- Additionally, there is an increase in the oxidation resistance because of the presence of aluminium in the coating as it has the property of increasing the oxidation resistance. So, there is an improvement in the corrosion resistance.

- We use titanium aluminium nitride coating instead of titanium nitride because of the increased Hardness properties of titanium aluminium nitride $(2600-3300 \mathrm{HV})$.

\subsection{Thermal Test}

In thermal test the design is done by using the CATIA V5 software. The disc is designed and the properties are given and we create an epoxy layer and the properties are given.

Then, the two layers are bonded and the thermal test is conducted for before coating and after coating conditions. In the after coating condition the titanium aluminium nitride layer is created and the properties are given and is bonded to the disc that was already designed.

Thus, by conducting a steady state thermal test the temperature generated on the specimen is reduced after coating with TiAlN.

Table 12: Steady State Thermal Analysis results

\begin{tabular}{|c|c|}
\hline Maximum temperature before coating & $90^{\circ} \mathrm{C}$ \\
\hline Maximum temperature after coating & $75^{\circ} \mathrm{C}$ \\
\hline
\end{tabular}

Also, the Heat flux for the specimen after coating it with TiAlN has increased thus, a faster heat dissipation can be witnessed during braking process.

Table 13: Heat Flux results

\begin{tabular}{|c|c|}
\hline Maximum Heat flux before coating & $0.58181 \mathrm{~W} / \mathrm{mm}^{\mathrm{a}}$ \\
\hline Maximum Heat flux after coating & $2.3907 \mathrm{~W} / \mathrm{mm}^{\mathrm{a}}$ \\
\hline
\end{tabular}

Thus, our project objective is to improve the wear and thermal resistance of disc brake rotor using titanium aluminium nitride coating. Thus, our results show a decrease of $6.09 \%$ in wear and increase in the thermal resistance by $20 \%$.

\section{References}

[1] Perillo, P.M., "Corrosion behavior of coatings of Tiatanium nitride and titanium-titanium nitride on steel substrates," Corrosion, 2006.62(2): p. 182-185.

[2] Baba. K and R. Hatada, "Corrosion-resistant titanium nitride coatings formed on stainless steel byion-beamassited deposition," Surface and Coatings Technology, 1994.66(1-3 pt 2)

[3] S. Kalpakjian and S. R. Schmid, "Manufacturing Processes for Engineering Materials," Second Ed. Addison-Wesley Publishing Company, New York, USA, (1992).

[4] Farooq M. and Lee Z. H. (2002), "Optimization of the sputtering process for depositing composite Thin Films," Journal of the Korean Physical society, 40 (3) 511_515.

[5] Jochen Burgdorf and Helmuty Weisbrod, "Low-wear frictionally engaging device," International Standard Electric corporation, US 4715486 A.

[6] Giovanni Mario Tironi, Fabiano Carminatti, Lorenzo Cavalli and Laura Sammarelli., "A method of making a brake disc, brake disc for disc brake and a disc brake," WO 2014097186 A1.

[7] Manjunath T V, Dr Suresh P M, "Structural and Thermal Analysis of Rotor Disc of Disc Brake," International Journal of Innovative Research in Science, Engineering and Technology, ISSN: 2319-8753.

[8] Rakesh Jaiswal, Anupam Raj Jha, Anush Karki, Debayan Das, Pawan Jaiswal, Saurav Rajgadia and Ankit Basnet, "Structural and Thermal Analysis of Disc brake using Solidworks and Ansys," International journal of Mechanical Engineering and Technology, IJMET_07_01_008. 